\title{
Is High Body Mass Index in Elderly Harmless?
}

Keywords: High body mass index; Elderly and fasting hyperglycemia Abstract
A series of studies has defended higher body mass index (BMI) of
the elderly as preventive, but the obesity may play an important role
in the development of other diseases, such as, fasting hyperglycemia
that may progress to diabetes and in contrast, decreased physical
activity plays an important role in the onset of chronic diseases in
the elderly. The aim of this study was to investigate the relationship
between obesity, measured by body mass index (BMI) and the
physical activity level, assessed by the IPAQ as risk factors for fasting
hyperglycemia in older people. Methods: 803 elderly volunteers who
participate in the project EPIDOSO II from the Center for the Study
of Aging - Federal University of São Paulo was part of the research.
This is a prospective cohort study assessing the elderly in the SP. This
elderly population is evaluated by many health professionals through
medical, physical, nutritional and psychological evaluations. It is also
performed blood exams for the measurement of fasting glucose.
Laboratory results were related to body mass index and physical
activity level of each individual. The results showed that obesity and
decreased physical activity can lead to changes in fasting glucose.
This study makes us rethink the tolerance of a higher BMI in the elderly
population, proving the relationship of metabolic risk with increasing
BMI and low Intemational Physical Activity Questionnaires (IPAQ).

\section{Introduction}

The world population is rapidly aging. This demographic transition presents both opportunities and challenges for aging researchers. The physiological process of ageing changes the body composition and great loss of lean body mass can be verified. This loss of lean body mass is responsible for the distribution of glucosemediated insulin and an increased visceral fat, both factors contribute to glucose metabolism disorders, which favors the insulin resistance. However, ageing itself is associated with the alteration of pancreatic $\beta$ cells, which leads to fasting hyperglycemia $[1,2]$.

According to the American Diabetes Association [3], fasting hyperglycemia can be defined as an intermediate state between normal glucose tolerance and type 2 diabetes, characterizing the levels of fasting plasma glucose values in between 100 to $125 \mathrm{mg} / \mathrm{dl}$ or 6.1 to $6.9 \mathrm{mmol} / \mathrm{l}$.

Major concern is the development of fasting hyperglycemia in the elderly because studies have shown that the change in fasting glucose can develop into diabetes, a disease with a high risk of morbidity and mortality from cardiovascular disease, including myocardial infarction, left ventricular hypertrophy, heart failure and stroke $[4,5]$. All these factors can be anticipated when there is an increase in body mass $[6,7]$.

This study was motivated by the need for a deeper knowledge of obesity and fasting hyperglycemia in people over 60 years, based on the high prevalence of weight gain in the general population and the degree of obesity, inaccurate definitions related to health problems in the elderly, as well as the need for characterization of interrelated factors to obesity in this age group.

\section{Journal of Geriatrics and Palliative Care}

Mayra Dos Santos Silva ${ }^{1 *}$, Caroline Moreira Bazzana ${ }^{1}$, Luiz Roberto Ramos ${ }^{1}$, Sergio Tufik ${ }^{2}$, Lígia M. Lucchesi ${ }^{2}$ and Guiomar Silva Lopes ${ }^{1}$

${ }^{1}$ Department of Preventive Medicine, Universidade Federal de São Paulo, São Paulo, Brazil

${ }^{2}$ Sleep Medicine and Biology Disciplines, Psychobiology Department, Universidade Federal de São Paulo, São Paulo, Brazil

\section{Address for Correspondence}

Mayra Dos Santos Silva, Department of Preventive Medicine, Universidade Federal de São Paulo, Rua Eduardo Cantor, 256 CEP: 02979-180 São Paulo, Brazil, E-mail: mayra.santos@ig.com.br

Copyright: (c) 2015 Silva MD, et al. This is an open access article distributed under the Creative Commons Attribution License, which permits unrestricted use, distribution, and reproduction in any medium, provided the original work is properly cited.

Submission: 03 February 2015

Accepted: 30 March 2015

Published: 04 April 2015

The transport of glucose into cells is impaired in obese people [8], the insulin secretion is increased, while liver uptake decreased with decreased peripheral insulin effectiveness [9]. It is believed that the body fat alter the insulin signaling pathway, leading to decreased uptake of circulating glucose [10]. According to the weight and adiposity increase, increase the beta cells to compensate for insulin output the resulting decline in sensitivity to this hormone. This littleknown adaptive response becomes increasingly ineffective in the elderly, leading to an intensification of hyperglycemia [11].

Despite all the correlations between obesity, metabolic changes and cardiovascular disease, in 1987, Manson et al. in their review of 50 studies, drew the attention to the methodological issues in an obesity - mortality relationship [12]. Their studies showed no positive association or even an inverse association between weight and total mortality. Based on this study, many researchers have adopted a high BMI as a preventive index in the elderly population, taking into account the loss of lean mass and sarcopenia in the elderly [13].

Study by Beleigoli noted that BMI in the overweight or obese class I bands (according to World Health Organization), were associated with aging [14]. But the secular trend in increasing obesity appears to occur in parallel with the reduction in physical activity [15]. However, it is very difficult to establish a cause and effect relationship between body mass index and the degree of physical activity, but it is known that the reduction in daily physical activity directly and indirectly affects the daily energy expenditure of the individual. The three main components of daily energy expenditure are: basal metabolic rate, the thermic effect of food and physical activity [16]. Several authors have demonstrated an inverse relationship between basal metabolic rate in animals and BMI as well as reduced basal metabolic rate and body weight gain in humans [17]. Therefore, the lifestyle and dietary habits appear to represent a major risk factor in the development of obesity worldwide.

Furthermore, physical activity is related to glycemic control of the insulin sensitizing effect of the exercise as well as the stimulation of glucose uptake independently of insulin action [18].

Thus, the aim of this study was to investigate the relationship 
Citation: Santos Silva MD, Bazzana CM, Ramos LR, Tufik S, Lucchesi LM, et al. Is High Body Mass Index in Elderly Harmless? J Geriatrics Palliative Care 2015;3(1): 4.

ISSN: 2373-1133

between obesity, measured by body mass index (BMI) and the physical activity level, assessed by the IPAQ as risk factors for fasting hyperglycemia in older people.

\section{Material and Method}

803 elderly, both genders were included. These patients ranged in age from 61 to 82 years and were predominantly female and were evaluated over the past four years. This elderly population is part of a prospective cohort study called EPIDOSO, which includes people over 60 years or older, with the inclusion of a probabilistic population sample of elderly residents of the neighborhood of Vila Clementino in São Paulo.

All the participants signed an informal consent and underwent medical evaluation to fill out the Comprehensive Geriatric Assessment (CGA), which consists of several evaluations and laboratory tests.

According to the height and weight of the patient, the body mass index was estimated, given by the formula weight divided by the height ${ }^{2}$. It is considered BMI at a normal standard from 19 to 25. Individuals who perceived body mass index between 25 and 30 $\mathrm{kg} / \mathrm{m}^{2}$ were considered overweight and those with BMI> 30 were considered obese. The level of definition of obesity remains the same in the elderly population, despite the existence of a higher tolerance of the elderly with increasing BMI and then obesity is defined for a higher level of BMI in this age group [13].

In order to evaluate the level of physical activity of the elderly, we used the International Physical Activity Questionnaire (IPAQ). An individual was considered active when the international physical activity questionnaire has shown that he exercises for a period of time superior to $150 \mathrm{~min}$ per week.

\section{Statistical Analysis}

Data were analyzed by Statistical Software Package (PASW Statistics for Windows, version 19.0; SPSS Inc; Chicago, IL). Categorical data were analyzed by chi square $\left(\mathrm{X}^{2}\right)$ and odds ratio test (OR).

We used logistic regression model to predict the likelihood of a person having high blood glucose, using as an explanatory variable the sex, IPAQ and BMI.

We considered p: 0.05 .

\section{Results}

The studied population considered was about 72 years old (average), higher predominance of women $(64,7 \%)$ and BMI was equal to $(27,16)$. We have noticed an increase in BMI $(27,22)$ and fasting blood glucose $(105,7 \mathrm{mg} / \mathrm{dl})$ in shown in Table 1 .

Table 2 shows the relationship between the IPAQ and BMI, there is an association between sedentary and hyperglycemia $\left(X^{2}=4.67, p\right.$ $=0: 03)$, which presented a risk of OR: 1:42 (1.03-1.97).

Table 3 shows the association between Fasting hyperglycemia, IPAQ and BMI.
Table 1: Complete description of IPAC, BMI and Glycemia.

\begin{tabular}{|c|c|c|c|}
\hline \multicolumn{2}{|l|}{ Variables } & $\mathbf{n}$ & Mean $\pm S D$ \\
\hline \multicolumn{2}{|l|}{ Age (years) } & 802 & $72.67 \pm 7.52$ \\
\hline \multicolumn{2}{|l|}{$\operatorname{Sex}(M / F)-n(\%)$} & 802 & $\begin{array}{l}283(35.3 \%) \\
519(64.7 \%)\end{array}$ \\
\hline \multicolumn{2}{|l|}{ BMI $\left(\mathrm{Kg} / \mathrm{m}^{2}\right)$} & 802 & $27.22 \pm 4.86$ \\
\hline \multicolumn{2}{|l|}{ Glucose (mg/dl) } & 802 & $105.7 \pm 29.7$ \\
\hline \multicolumn{2}{|l|}{ IPAQ } & 802 & $408.18 \pm 74.86$ \\
\hline Description & IPAQ & BMI & Glycemia \\
\hline Mean & 408.2 & 27.22 & 105.7 \\
\hline Median & 270 & 26.8 & 99 \\
\hline Standard deviation & 748.6 & 4.68 & 29.7 \\
\hline $\mathrm{CV}$ & $183 \%$ & $17 \%$ & $28 \%$ \\
\hline Q1 & 120 & 24.2 & 91 \\
\hline Q3 & 510 & 29.73 & 110 \\
\hline Min & 0 & 15.81 & 14 \\
\hline Max & 16.320 & 46 & 361 \\
\hline $\mathrm{N}$ & 721 & 736 & 751 \\
\hline $\mathrm{Cl}$ & 54.6 & 0.34 & 2.1 \\
\hline
\end{tabular}

CV: Coefficient of Variation; Min: Minimum; Max: Maximum; Cl: Confidence Interval

Table 2: Association between physical levels (sedentary and active) and changes in glucose.

\begin{tabular}{|l|c|c|c|c|c|}
\hline \multirow{2}{*}{ Glucose } & & & \multicolumn{3}{|c|}{ IPAQ } \\
\hline & Risk & $\mathrm{N}$ & 238 & 198 & 436 \\
\hline & & $\%$ & $54.90 \%$ & $45.10 \%$ & $54.10 \%$ \\
\hline & Normal & $\mathrm{N}$ & 104 & 262 & 366 \\
\hline Total & & $\%$ & $28.00 \%$ & $71.00 \%$ & $45.90 \%$ \\
\hline & & $\mathrm{N}$ & 342 & 460 & 802 \\
\hline & & $\%$ & $100.00 \%$ & $100.00 \%$ & $100.00 \%$ \\
\hline
\end{tabular}

$\mathrm{X}^{2},{ }^{*} \mathrm{p}<0.05$

We have notice that the final model is composed only of IPAC and BMI. The model was defined as:

$$
\text { Glicemia }=\frac{\exp ^{-0,3067-0,4408 * I P A C+0,7050 * I M C}}{1+\exp ^{-0,3067-0,4408 * I P A C+0,7050 * I M C}}
$$

We verify the adherence of the model, which means, we test the model to see if it can identify (predict) the likelihood that the individual to have abnormal blood glucose.

We verified that the model is adherent (Table 4), as in the three tests we performed to measure adherence, we did not find significance and therefore we consider that the model is good and has good adherence.

\section{Discussion}

The main finding of this study was the association between high body mass index and fasting hyperglycemia, where both are justified by a low level of physical activity.

This result is equal to the result of a cross-sectional study, which considered a population of 106 elderly and showed overweight and 
Citation: Santos Silva MD, Bazzana CM, Ramos LR, Tufik S, Lucchesi LM, et al. Is High Body Mass Index in Elderly Harmless? J Geriatrics Palliative Care 2015;3(1): 4.

ISSN: 2373-1133

Table 3: Coefficients of the logistic regression model.

\begin{tabular}{|c|c|c|c|c|c|c|}
\hline & \multicolumn{2}{|c|}{ Initial } & & \multicolumn{2}{c|}{ Final } \\
\hline & Coefficient & P-valor & Coefficient & P-valor & Odds ratio & Lower \\
\hline Constant & 0.0873 & 0.765 & -0.3067 & 0.119 & 0.013 & 0.64 \\
\hline IPAQ & -0.4745 & 0.009 & -0.4408 & 0.45 & 0.91 \\
\hline BMI & 0.7107 & $<0.001$ & 0.7050 & $<0.001$ & 2.02 \\
\hline
\end{tabular}

Table 4: Tests of adherence of Logistic Regression model.

\begin{tabular}{|l|c|c|}
\hline Method & Initial & Final \\
\hline Pearson & 0.454 & 0.986 \\
\hline Deviance & 0.020 & 0.986 \\
\hline Hosmer-Lemeshow & 0.916 & 0.988 \\
\hline
\end{tabular}

inadequate food intake in the elderly population, prevailing the presence of metabolic changes [17].

There is a wide variation in the prevalence of obesity in the geriatric population and few studies have assessed this prevalence in different ways covering the different age groups of elderly. The significant decrease in obesity at the age of 80 years or older may suggest interference of obesity and the diseases associated with it, as factors that could be contributing to increased mortality of obese elderly who are younger than 80 . Also, the process of senescence could contribute to explain this difference, but the decrease in the occurrence of obesity is not an even event and also it is not progressively in the different age groups. In addition, there is no difference in the prevalence of obesity among the elderly aged from 60-69 years and from 70-79 years [19].

Fasting hyperglycemia is found at high frequency in the elderly and it has been shown that after the age of 50 years the levels of fasting glucose added 0:06 $\mathrm{mmol} / \mathrm{decade}$ and this is the reason why so many authors give credit to the hypothesis that progressive disorders of fasting may lead to glucose intolerance and type 2 diabetes $[1,2]$. Accordingly, a study done in 2001 demonstrated the prevalence of $83.8 \%$ of diabetics in the elderly population when the incidence and prevalence of type 2 diabetes increases sharply with increasing age [20].

Researches on obesity have shown an increased body mass index in the elderly population, which requires attention due to the risk of co-morbidities that increase progressively with BMI and the association with an increased risk of mortality [21,22].

According to our results, obesity is associated with increased fasting glucose levels, questioning the higher tolerance in relation to BMI of the elderly as proposed by some authors [13].

The relationship between obesity and increased fasting glucose was widely approached in literature and it is believed that there is a general inflammatory response in obesity with the production of these inflammatory mediators showing expression patterns and impact on the functioning of insulin $[23,24]$.

Our results also show correlation between physical inactivity with increased blood glucose levels. According to some authors [24,25], physical inactivity favored by modern life is a risk factor as important as improper diet in the etiology of obesity and has a positive and direct relationship with increasing incidence of type 2 diabetes in adults, regardless of body mass index or family history of diabetes.

Some studies show that weight control and increased physical activity decreases insulin resistance, decreasing the chances of developing diabetes mellitus [26]. The practice of regular physical activity promotes an increase in insulin sensitivity for increased hepatic uptake and improves the sensitivity of peripheral receptors [27]. In addition, physical activity, associated with a healthy diet, improves the lipid profile of individuals who are more likely to develop cardiovascular disease [28].

This study is important as it makes us reevaluate the tolerance of a higher BMI in the elderly population, proving the relationship of metabolic risk with increasing BMI. It is necessary to implement public policies encouraging physical activity at all ages, but in particular at old age, as a preventive form to avoid obesity and fasting hyperglycemia.

It would be interesting to keep up encouraging the practice of physical activity for the elderly population, subsequently measuring the benefits of this activity and the evolution of those individuals who do not adhere to physical activity.

\section{References}

1. Scheen AJ (2005) Diabetes mellitus in the elderly: insulin resistance and/or impaired insulin secretion? Diabetes Metab 31: 5S27-5S34.

2. Sone H, Kagawa $Y$ (2005) Pancreatic beta cell senescence contributes to the pathogenesis of type 2 diabetes in high-fat diet-induced diabetic mice. Diabetologia 48: 58-67.

3. American Diabetes Association (2004) Diagnosis and classification of diabetes mellitus. Diabetes Care 27: S5-S10.

4. Lorenzo C, Okoloise M, Williams K, Stern MP, Haffner SM (2003) The metabolic syndrome as predictor of type 2 diabetes: the San Antonio heart Study. Diabetes Care 26: 3153-3159.

5. Banerjee C, Moon YP, Paik MC, Rundek T, Mora-McLaughlin C, et al. (2012) Duration of diabetes and risk of ischemic stroke: the Northern Manhattan Study. Stroke 43: 1212-1217.

6. Oster G, Edelsberg J, O'Sullivan AK, Thompson D (2000) The clinical and economic burden of obesity in a managed care setting. Am J Manag Care 6: 681-689.

7. Mayer-Davis EJ, Costacou T (2001) Obesity and sedentary lifestyle: modifiable risk factors for prevention of type 2 diabetes. Curr Diab Rep 1: 170-176.

8. Chan JM, Rimm EB, Colditz GA, Stampfer MJ, Willett WC (1994) Obesity, fat distribution, and weight gain as risk factors for clinical diabetes in men. Diabetes Care 17: 961-969.

9. Wajchenberg BL, Santomauro ATMG, Santos RF (1992) Diabetes Melito insulino-dependente (Tipo II): diagnóstico, etiopatogenia e fisiopatologia. In: Wajchenberg BL, organizador. Tratado de endocrinologia clínica. São Paulo: Roca, p: 706-738.

10. Chandran M, Phillips SA, Ciaraldi T, Henry RR (2003) Adiponectin: more than 
Citation: Santos Silva MD, Bazzana CM, Ramos LR, Tufik S, Lucchesi LM, et al. Is High Body Mass Index in Elderly Harmless? J Geriatrics Palliative Care 2015;3(1): 4.

ISSN: $2373-1133$

just another fat cell hormone? Diabetes Care 26: 2442-2450.

11. Weyer C, Bogardus C, Mott DM, Pratley RE (1999) The natural history of insulin secretory dysfunction and insulin resistance in the pathogenesis of type 2 diabetes mellitus. J Clin Invest 104: 787-794.

12. Manson JE, Stampfer MJ, Hennekens CH, Willett WC (1987) Body weight and longevity. A reassessment JAMA 257: 353-358.

13. Stevens J (2000) Impact of age on associations between weight and mortality. Nut Rev 58: 129-137.

14. Beleigoli AMR (2012) Relações entre medidas antropométricas, peptídeo natriurético tipo $\mathrm{B}$ e mortalidade em dez anos de idosos do Estudo de Bambu sobre saúde e envelhecimento. Tese apresentada ao Programa de PósGraduação em Saúde do Adulto da Faculdade de Medicina da Universidade Federal de Minas Gerais.

15. Martinez JA (2000) Body-weight regulation: causes of obesity. Proc Nutr Soc 59: $337-345$

16. Yamaoka K, Tango T (2005) Efficacy of lifestyle education to prevent type 2 diabetes: a meta-analysis of randomized controlled trials. Diabetes Care 28: 2780-2786.

17. Albu J, Shur M, Curi M, Murphy L, Heymsfield SB, et al. (1997) Resting metabolic rate in obese, premenopausal black women. Am J Clin Nutr 66: 531-538

18. Persghin G, Price TB, Petersen KF, Roden M, Cline GW, et al. (1996) Increased glucose transport-phosphorylation and muscle glycogen synthesis after exercise training in insulin-resistant subjects. N Engl J Med 335: 13571362.

19. Weinsier RL, Hunter GR, Heini AF, Goran MI, Sell SM (1998) The etiology of obesity: relative contribution of metabolic factors, diet, and physical activity. Am J Med 105: 145-150.

20. Ortiz MC, Zanetti ML (2001) Survey on risk factors for type-2 diabetes mellitus at a higher education institution. Rev Lat Am Enfermagem 9: 58-63.

21. Lee IM, Manson JE, Hennekens CH, Paffenbarger RS Jr (1993) Body weight and mortality: A 27-year follow-up of middle aged men. JAMA 270: 28232828 .

22. Manson JE, Colditz GA, Stampfer MJ, Willett WC, Rosner B, et al. (1990) A prospective study of obesity and coronary heart disease in women. $N$ Engl $J$ Med 322: 882-889.

23. Miranda PJ, DeFronzo RA, Califf RM, Guyton JR (2005) Metabolic syndrome: definition, pathophysiology, and mechanisms. Am Heart J 149: 33-45.

24. Zimmet PZ, McCarty DJ, de Courten MP (1997) The global epidemiology of non-insulin-dependent diabetes mellitus and the metabolic syndrome. $J$ Diabetes Complications 11: 60-68

25. Pan XR, Li GW, Hu YH, Wang JX, Yang WY, et al. (1997) Effect of diet and exercise in preventing NIDDM in people with impaired glucose tolerance. The Da Qing IGT and Diabetes Study. Diabetes Care 20: 537-544.

26. O'donovan G, Kearney EM, Nevill AM, Woolf-May K, Bird SR (2005) The effects of 24 weeks of moderate- or high-intensity exercise on insulin resistance. Eur J Appl Physiol 95: 522-528.

27. Chang A, Halter JB (2003) Aging and insulin secretion. Am J Physio Endocrinol Metab 284: E7-E12.

28. Kokinos P, Myers J (2010) Exercise and physical activity. clinical outcomes and applications. Circulation 122: 1637-1648.

\section{Acknowledgements}

We thank the Agency for Support and Evaluation of Graduate Education (CAPES) and Research Incentive Fund Association (AFIP) for its support of this research. 